Check for updates

Cite this: RSC Adv., 2021, 11, 4270

Received 24th October 2020 Accepted 11th January 2021

DOI: $10.1039 / \mathrm{dOra09090e}$

rsc.li/rsc-advances

\title{
Blackening of titanium dioxide nanoparticles by atomic hydrogen and the effect of coexistence of water on the blackening
}

\author{
Masahide Fujimoto, ${ }^{a}$ Masuaki Matsumoto, (D) *a Naoki Nagatsuka (iD $\dagger^{b}$ \\ and Katsuyuki Fukutani (iD *bc
}

\begin{abstract}
A fast blackening process of titanium dioxide nanoparticles by exposing to atomic hydrogen was studied by estimating the color of the nanoparticles. The whiteness of $\mathrm{TiO}_{2}$ decreased exponentially with time, which suggests a first-order reaction between atomic $\mathrm{H}$ and surface oxygen, whose rate constant is proportional to the ambient pressure of $\mathrm{H}_{2}$. The rate constant increases as the temperature of nanoparticles at exposing to atomic hydrogen. The structure and size of nanoparticles were estimated by the X-ray diffraction (XRD), which shows that a part of anatase transferred to rutile and the crystal sizes of both anatase and rutile increased by hydrogenation above $600 \mathrm{~K}$. The blackening of $\mathrm{TiO}_{2}$ halfway stopped under the condition of the similar partial pressure of water with hydrogen. This suggests the presence of reverse reaction between $\mathrm{H}_{2} \mathrm{O}$ and oxygen vacancy, whose reaction rate constant is proportional to the partial pressure of $\mathrm{H}_{2} \mathrm{O}$.
\end{abstract}

\section{Introduction}

Titanium dioxide $\left(\mathrm{TiO}_{2}\right)$ is one of the most widely used photocatalysts and has been extensively studied after the pioneering work by Fujishima and Honda., ${ }^{\mathbf{1} 2}$ Since the band-gap of $\mathrm{TiO}_{2}$ is wide (about $3 \mathrm{eV}$ ), it can absorb only ultraviolet light, which is contained only several \% in the solar light. Therefore, many efforts have been made to improve the optical absorption of $\mathrm{TiO}_{2}$ under the solar light, such as generation of donor or acceptor states in the band gap by doping impurities ${ }^{3-6}$ or production of $\mathrm{Ti}^{3+}$ by self-doping. ${ }^{7}$ An alternative approach to improve absorption of solar light was proposed by Chen et al., ${ }^{8-10}$ and reviewed by Liu et al. ${ }^{11}$ Chen et al. hydrogenated the anatase $\mathrm{TiO}_{2}$ nanoparticles in a 20 bar $\mathrm{H}_{2}$ atmosphere at about $473 \mathrm{~K}$ for 5 days. While the color of natural $\mathrm{TiO}_{2}$ nanoparticles is white, it changed to black by hydrogenation, therefore, it is called the black $\mathrm{TiO}_{2}$ (titania). The narrowing of the band gap was confirmed by X-ray photoelectron spectroscopy and the acceleration of photocatalytic decomposition of methylene blue was observed. Disordering of the outer region of nanoparticles was also observed by high-resolution

\footnotetext{
${ }^{a}$ Tokyo Gakugei Univ., 4-1-1 Nukui-kita-machi, Koganei-shi, Tokyo 184-8501, Japan. E-mail: masuaki@u-gakugei.ac.jp

${ }^{b}$ Institute of Industrial Science, The University of Tokyo, 4-6-1 Komaba, Meguro-ku, Tokyo 153-8505, Japan. E-mail: fukutani@iis.u-tokyo.ac.jp

${ }^{c}$ Advanced Science Research Center, Japan Atomic Energy Agency, Tokai, Ibaraki 3191195, Japan

$\uparrow$ Present address: Department of Chemistry, Graduate School of Science, Kyoto University, Kyoto 606-8502, Japan.
}

transmission electron microscopy, which they attributed to the cause of the blackening and the band gap narrowing of $\mathrm{TiO}_{2}$. Selcuk et al. studied the formation mechanism and structure features of the black $\mathrm{TiO}_{2}$ using the first-principles-validated reactive force field molecular dynamics simulations and revealed that surface oxygen vacancies were created by reaction with $\mathrm{H}_{2}$ and its diffusion into bulk is inhibited by a high barrier in the subsurface region, which initiates surface disordering, and that this hydrogenated amorphous shell has a key role in the photoactivity of the black $\mathrm{TiO}_{2} \cdot{ }^{12}$ The interaction of hydrogen with $\mathrm{TiO}_{2}$ has been extensively studied both experimentally and theoretically. ${ }^{2}$ The reduction of $\mathrm{TiO}_{2}$ and the production of oxygen vacancies or $\mathrm{Ti}^{3+}$, which modify the electronic structure, can be easily caused by vacuum annealing, hydrogen adsorption, electron irradiation, ultraviolet light irradiation, or exposure to molecular or atomic hydrogen. ${ }^{13-16}$ Among these procedures, the exposure to atomic hydrogen is expected to reduce the $\mathrm{TiO}_{2}$ surface effectively. In this paper, the blackening of the $\mathrm{TiO}_{2}$ nanoparticles by exposing to atomic hydrogen was studied at various sample temperatures and ambient $\mathrm{H}_{2}$ pressures. Since $\mathrm{H}_{2} \mathrm{O}$ is expected to be one of the products by the reduction of $\mathrm{TiO}_{2}$ by hydrogen and it was reported that the presence of water affects the stability of oxygens and oxygen vacancies at the surface and subsurface sites, ${ }^{17}$ the effect of partial pressure of $\mathrm{H}_{2} \mathrm{O}$ on the blackening was also studied.

\section{Experimental}

Blackening of $\mathrm{TiO}_{2}$ nanoparticles was performed in a highvacuum chamber, whose base pressure was about $10^{-4} \mathrm{~Pa}$. 
The anatase $\mathrm{TiO}_{2}$ nanoparticles with an average diameter of $8 \mathrm{~nm}$ (ST-01, Ishihara Sangyo Kaisha, Ltd.) were put on a W boat, which could be heated up to $873 \mathrm{~K}$ measured by the type $\mathrm{K}$ thermocouple. The temperature of the $\mathrm{W}$ boat is called the hydrogenation temperature below. The atomic hydrogen was produced by a W filament that was placed about $5 \mathrm{~mm}$ from the boat. The filament was heated at about $1973 \mathrm{~K}$ by direct current, of which temperature was monitored by a pyrometer. It was reported that the cracking efficiency of $\mathrm{H}_{2}$ was $1.5 \%$ at $1873 \mathrm{~K}$ and increases exponentially with $\mathrm{W}$ filament temperature, which suggests that the atomic hydrogen can be efficiently produced at $1973 \mathrm{~K}^{\mathbf{1 8}}$

After setting the temperature of the $\mathrm{W}$ boat and filament at appropriate temperatures, photos of the sample were taken every several seconds. The whiteness of the sample was estimated from the numerical value of the 8 bit digitized monochrome image by using an imaging software. After introducing $\mathrm{H}_{2}$ into vacuum chamber, time evolution of the whiteness was obtained. The whiteness was normalized by the initial value of a series of the measurements. Since only the part of the nanoparticles facing to the $\mathrm{W}$ filament was blackened after a measurement of time evolution, the whiteness could be initialized by scrambling with a wobble stick and the next measurement was started. The speed of blackening largely depends on the distance between the sample and the $\mathrm{W}$ filament for $\mathrm{H}_{2}$ dissociation. It is necessary to put the $\mathrm{W}$ filament near the nanoparticles to blacken them quickly. Though the distance affects the temperature of the sample, this effect is included in the increase of the hydrogenation temperature. It is therefore suggested that the efficient incidence of atomic hydrogen is important for the effective blackening of $\mathrm{TiO}_{2}$.

Structural phase and average size of the nanoparticles were estimated by X-ray diffraction (XRD: Ultima IV, RIGAKU). The fraction of anatase was estimated by the integrated peak intensities for the anatase and rutile. The average size $(D)$ of the nanoparticles was estimated by the Scherrer equation

$$
D=\frac{K \lambda}{\beta \cos \theta},
$$

where $\beta$ was the full-width at half-maximum (FWHM) obtained by the Lorentzian-fitted diffraction peak, $\theta$ is the angle of the peak of XRD, $\lambda$ $=0.1541 \mathrm{~nm}$ is the wavelength of $\mathrm{Cu} \mathrm{K} \alpha$ and $K=0.9$ is the form factor.

\section{Results}

The temperatures of $\mathrm{TiO}_{2}$ nanoparticles and $\mathrm{W}$ filament were kept at $573 \mathrm{~K}$ and $1973 \mathrm{~K}$, respectively, for about $30 \mathrm{~min}$ to get the stable states, and $\mathrm{H}_{2}$ was introduced in vacuum at $t=0$. When the ambient $\mathrm{H}_{2}$ pressure $\left(p_{\mathrm{H}_{2}}\right)$ was kept constant at a fixed pressure from $5.0 \times 10^{-3} \mathrm{~Pa}$ to $1.0 \times 10^{-1} \mathrm{~Pa}$, the color of the nanoparticles changed from white to black and sintering occurred in a few minutes. The particle size increased by sintering. When the sample was treated without introducing $\mathrm{H}_{2}$ (at the base pressure of $10^{-4} \mathrm{~Pa}$ ), only the sintering occurred but the color of the nanoparticles hardly changed. Time evolutions of the whiteness of $\mathrm{TiO}_{2}$ nanoparticles at various $p_{\mathrm{H}_{2}}$ are shown in Fig. 1. As shown in the figure, the whiteness decreased almost exponentially with time and the time constant became smaller as the ambient $\mathrm{H}_{2}$ pressure was increased.
Time evolutions of the whiteness of $\mathrm{TiO}_{2}$ nanoparticles at various hydrogenation temperatures $\left(T_{\mathrm{s}}\right)$ are shown in Fig. 2. The whiteness initially decreased exponentially, and the initial time constants $\tau_{1}$ decreased as the hydrogenation temperature increased. Decreasing curves of the whiteness deviate from the exponential functions at the low whiteness region.

Though the $\mathrm{TiO}_{2}$ nanoparticles could be blackened in a few minutes under the low ambient $\mathrm{H}_{2}$ pressures, the blackening only occurs at the upper side of the nanoparticles facing to the filament for $\mathrm{H}_{2}$ dissociation, which means that the atomic hydrogen is indispensable for the blackening of $\mathrm{TiO}_{2}$. It is necessary to scramble the nanoparticles every several minutes by the wobble stick to get the uniform black nanoparticles for the XRD experiments.

XRDs for the pristine white $\mathrm{TiO}_{2}$ and the heated ones without and with exposure to hydrogen are shown in Fig. 3 and 4, respectively. The parameters of the XRD are summarized in Table 1 . The $\mathrm{TiO}_{2}$ nanoparticles were not blackened without exposure to hydrogen. Only one peak can be observed at $25.3^{\circ}$ for the pristine white $\mathrm{TiO}_{2}$ nanoparticles. The peak position did not change by heating the white $\mathrm{TiO}_{2}$ nanoparticles without exposure to hydrogen. The peak width slightly narrowed by heating, which means that the average crystal size slightly increased from $7.32 \mathrm{~nm}$ to $8.36 \mathrm{~nm}$.

Blackening of $\mathrm{TiO}_{2}$ was caused by heating under exposure to the atomic hydrogen. XRDs for the black $\mathrm{TiO}_{2}$ produced at the

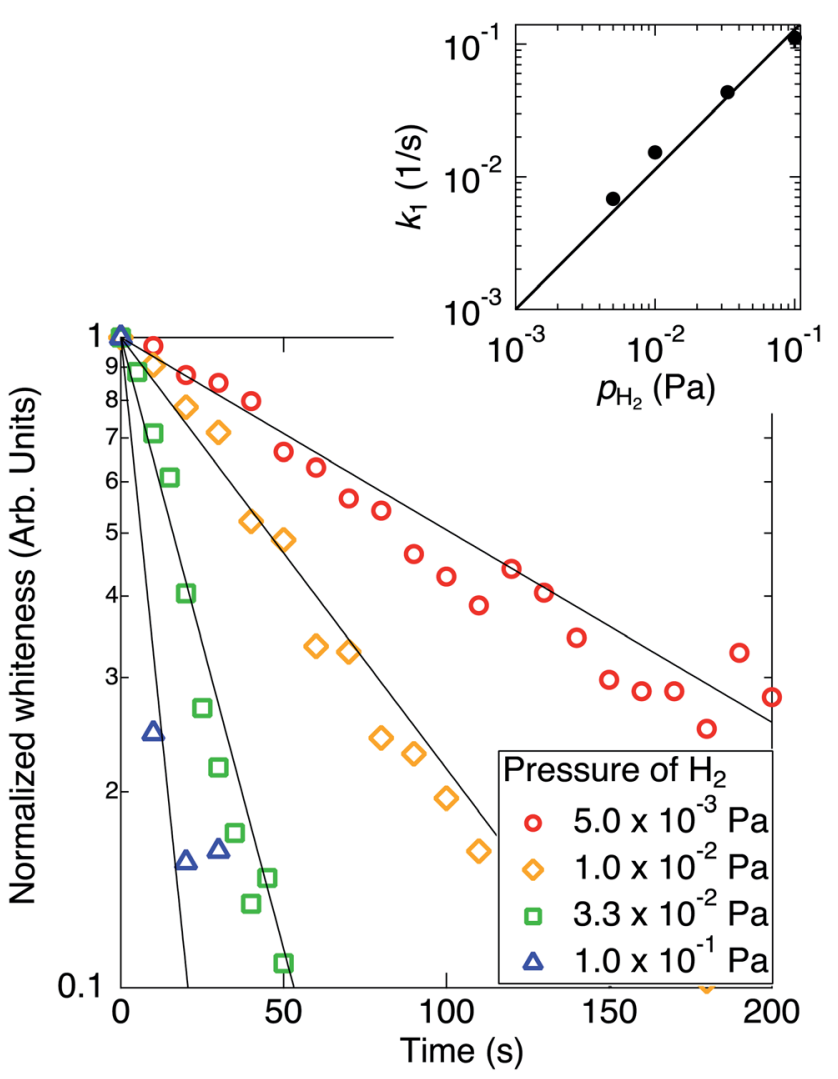

Fig. 1 Semi-logarithmic plot of the time evolutions of the normalized whiteness of $\mathrm{TiO}_{2}$ nanoparticles at various ambient pressures of $\mathrm{H}_{2}$ from $5.0 \times 10^{-3} \mathrm{~Pa}$ to $1.0 \times 10^{-1} \mathrm{~Pa}$. The temperatures of nanoparticles and $\mathrm{W}$ filament were kept at $573 \mathrm{~K}$ and $1973 \mathrm{~K}$, respectively. (Inset) Double logarithmic plot of the inverse values of initial time constants against the $\mathrm{H}_{2}$ pressures. 


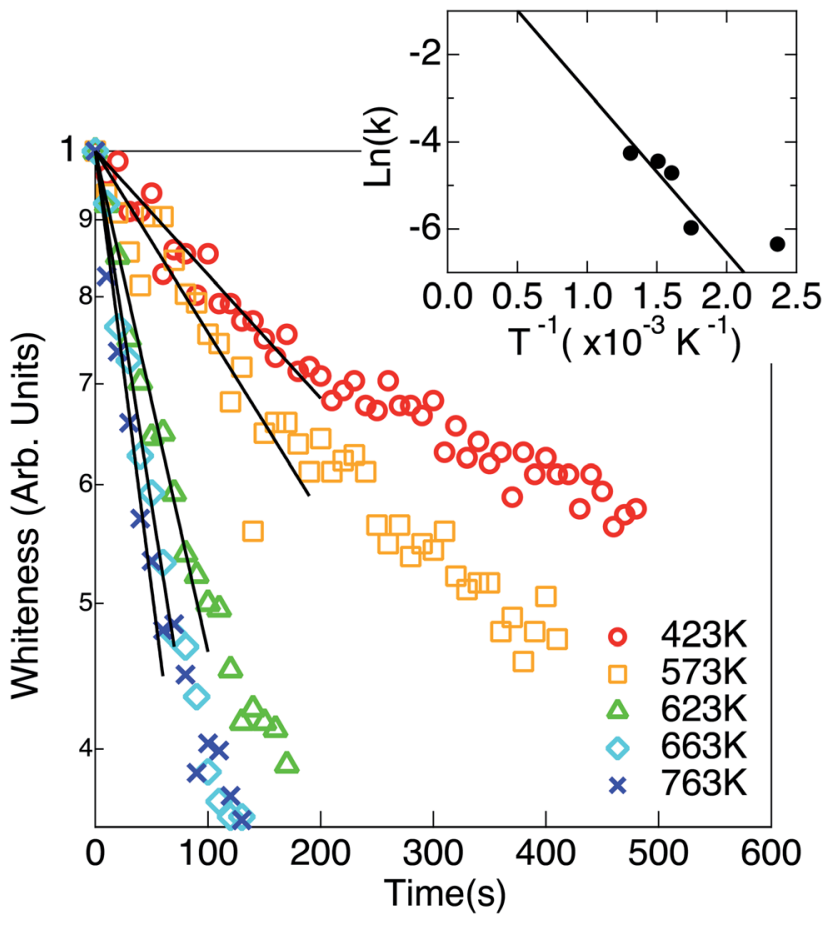

Fig. 2 Semi-logarithmic plot of the time evolutions of the normalized whiteness of $\mathrm{TiO}_{2}$ nanoparticles at various hydrogenation temperatures from $423 \mathrm{~K}$ to $763 \mathrm{~K}$. The temperature $\mathrm{W}$ filament was kept at $1973 \mathrm{~K}$ and the ambient $\mathrm{H}_{2}$ pressure was kept at $1.0 \times 10^{-2} \mathrm{~Pa}$. The exponentially fitted curves using initial evolutions are plotted by the solid lines. (Inset) Semi-logarithmic plot of the inverse values of initial time constants against the inverse of temperature.

hydrogenation temperatures of $440 \mathrm{~K}, 673 \mathrm{~K}$ and $773 \mathrm{~K}$ are shown in Fig. 4. XRD for the pristine white $\mathrm{TiO}_{2}$ is also shown for comparison. The width of the peak at $25.3^{\circ}$ narrowed by heating, which suggests that the average crystal size increased from $7.32 \mathrm{~nm}$ to $13.3 \mathrm{~nm}, 22.9 \mathrm{~nm}$ and $31.6 \mathrm{~nm}$ by heating at $440 \mathrm{~K}, 673 \mathrm{~K}$ and $773 \mathrm{~K}$, respectively. Besides the change in the peak width, another new peak appeared at $27.4^{\circ}$ after blackening at and above $673 \mathrm{~K}$. The peak at $25.3^{\circ}$ and $27.4^{\circ}$ could be assigned to the anatase (101) and rutile (110), respectively, which means that a part of the original anatase $\mathrm{TiO}_{2}$ transferred to rutile at high hydrogenation temperatures. The fractions of anatase were estimated by the integrated intensities of the two peaks. Temperature dependences of the fraction of anatase and the crystal sizes are shown in Fig. 5. They are also summarized in Table 1. As the hydrogenation temperature was increased, the fraction of anatase started to decrease above 500-600 K, from $100 \%$ at $440 \mathrm{~K}$ to $50 \%$ at $780 \mathrm{~K}$. The crystal sizes also increased as the hydrogenation temperature increased. This result is consistent with the previous reports by Mao et al., which showed that the phase transition from anatase to rutile is accelerated by $\mathrm{H}_{2}$ annealing. ${ }^{19}$

Finally, the effect of coexistence of water impurity was researched. Time evolutions of the whiteness at the partial pressures of $\mathrm{H}_{2} \mathrm{O}\left(p_{\mathrm{H}_{2} \mathrm{O}}\right)$ of $3.5 \times 10^{-3} \mathrm{~Pa}, 5.7 \times 10^{-3} \mathrm{~Pa}, 1.0 \times$ $10^{-2} \mathrm{~Pa}$ and $1.4 \times 10^{-2} \mathrm{~Pa}$ are shown in Fig. 6 . The base pressure before introducing water was $5.0 \times 10^{-5} \mathrm{~Pa}$. After setting

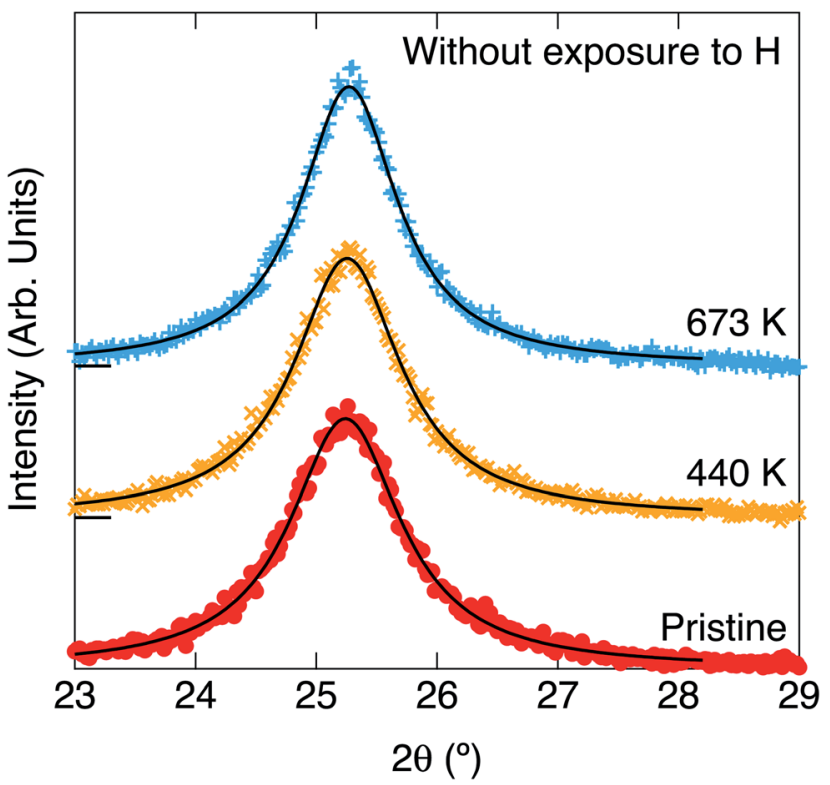

Fig. 3 X-ray diffraction spectra of the pristine white anatase nanoparticles and after annealing at $440 \mathrm{~K}$ and $673 \mathrm{~K}$ without exposure to hydrogen. The blackening did not occur. The peaks at $2 \theta=25.2^{\circ}$ is from anatase (101). The Lorentzian fitted curves were drawn by the solid lines.

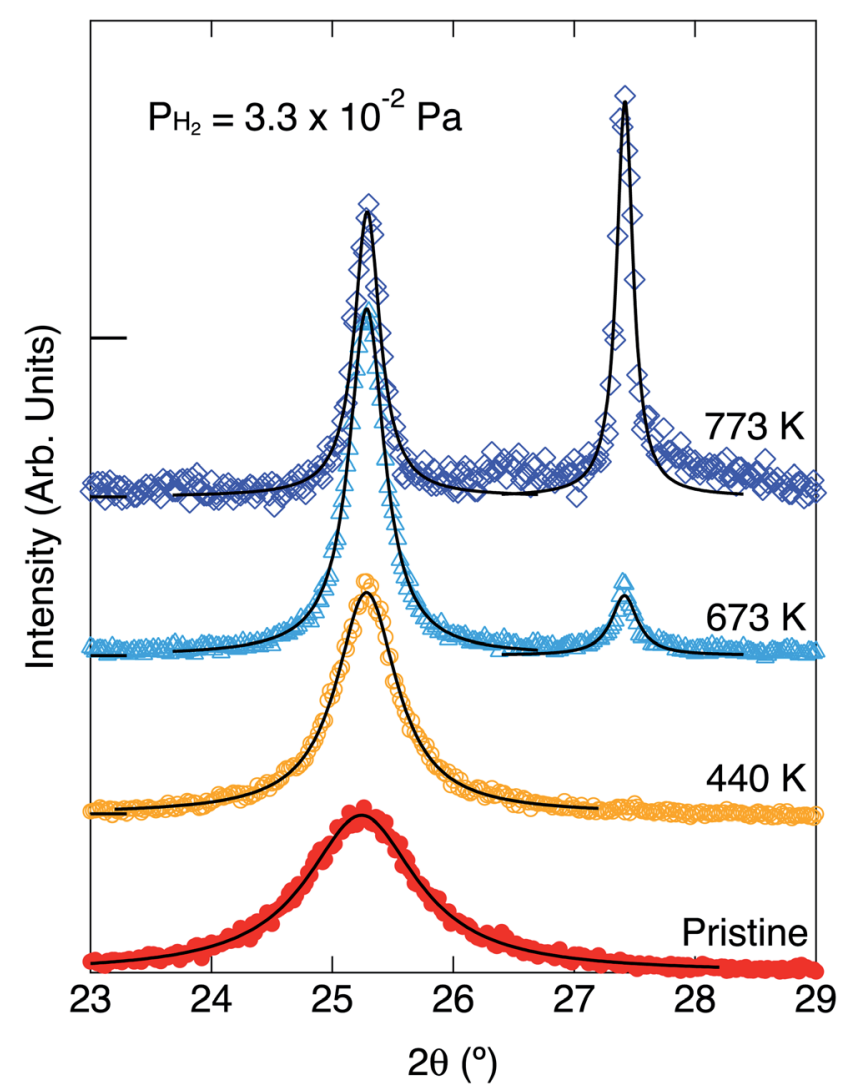

Fig. $4 \mathrm{X}$-ray diffraction spectra of the pristine white anatase nanoparticles and the black $\mathrm{TiO}_{2}$ produced at $440 \mathrm{~K}, 573 \mathrm{~K}, 673 \mathrm{~K}$ and $773 \mathrm{~K}$. The peaks at $2 \theta=25.2^{\circ}$ and $2 \theta=27.5^{\circ}$ are from anatase (101) and rutile (110), respectively. The Lorentzian fitted curves were drawn by the solid lines. 
Table 1 Table of the color (black or white) and the crystal structure (anatase or rutile) of $\mathrm{TiO}_{2}$, the presence of hydrogen at heating (yes/no), the sample temperature at heating or hydrogenation $\left(T_{s}\right), 2 \theta$ at the peak, the width of the peak, the fraction of anatase, the size of nanoparticles are shown

\begin{tabular}{|c|c|c|c|c|c|c|c|}
\hline Color (B/W) & Anatase/rutile & H exposure & $T_{\mathrm{s}}(\mathrm{K})$ & $\begin{array}{l}\text { Peak } 2 \theta \\
\left({ }^{\circ}\right)\end{array}$ & $\begin{array}{l}\text { Peak width } \\
\left({ }^{\circ}\right)\end{array}$ & Fraction & $\begin{array}{l}\text { Crystal size } \\
(\mathrm{nm})\end{array}$ \\
\hline $\mathrm{W}$ & $\mathrm{A}$ & $\mathrm{n}$ & - & 25.2 & 1.112 & 1 & 7.32 \\
\hline $\mathrm{W}$ & $\mathrm{A}$ & $\mathrm{n}$ & 673 & 25.3 & 0.9745 & 1 & 8.36 \\
\hline B & $\mathrm{A}$ & $\mathrm{y}$ & 440 & 25.3 & 0.6104 & 1 & 13.3 \\
\hline B & $\mathrm{A}$ & $\mathrm{y}$ & 673 & 25.3 & 0.3552 & 0.89 & 22.9 \\
\hline $\mathrm{B}$ & $\mathrm{R}$ & $\mathrm{y}$ & 773 & 27.4 & 0.1647 & 0.47 & 49.7 \\
\hline
\end{tabular}

the partial pressures of $\mathrm{H}_{2} \mathrm{O}$ to respective values, the temperatures of nanoparticles and W filament were kept at $573 \mathrm{~K}$ and $1973 \mathrm{~K}$, respectively, for about $30 \mathrm{~min}$, and $\mathrm{H}_{2}$ with a partial pressure of 3.3 $\times 10^{-2}$ Pa was introduced into the chamber at $t=0 \mathrm{~s}$. As shown in Fig. 6, the whiteness decreased exponentially, but they saturated to the larger values than those in Fig. 1, which means that the blackening of $\mathrm{TiO}_{2}$ nanoparticles halfway stopped.

\section{Discussion}

It is thought that the disordering of the outer region of the nanoparticles is related to the blackening from the results by HRTEM. $^{8}$ This disordering is thought to be caused by the reduction of $\mathrm{TiO}_{2}$, which produces oxygen vacancies and/or interstitial hydrogen near the surface. Since the production of $\mathrm{OH}$ does not cause blackening ${ }^{\mathbf{1 6}}$ and the $\mathrm{H}$ amount is confirmed to be smaller than 1 atomic\% by nuclear reaction analysis, ${ }^{21}$ the production of oxygen vacancies is focused and discussed in this manuscript.

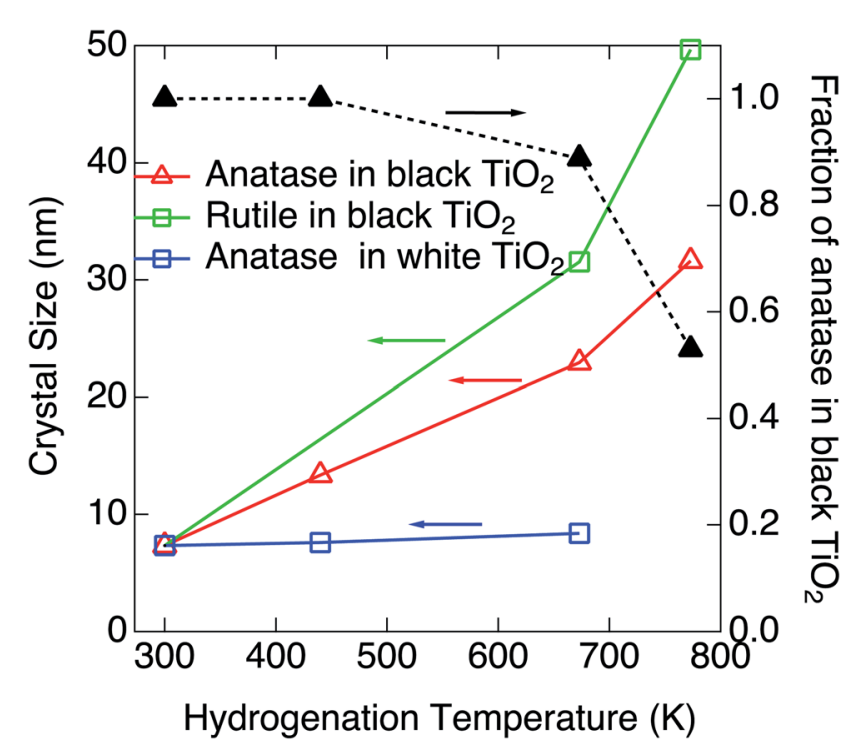

Fig. 5 Hydrogenation temperature dependences of the fraction of anatase and the size of nanoparticles and crystal structure at a fixed ambient $\mathrm{H}_{2}$ pressure of $3.3 \times 10^{-2} \mathrm{~Pa}$.
The reaction between the atomic hydrogen from the high temperature $\mathrm{W}$ filament and the surface oxygen $\left(\mathrm{O}_{\mathrm{s}}\right)$ of $\mathrm{TiO}_{2}$ nanoparticles can be written by the following formula. ${ }^{\mathbf{1 1 2}}$

$$
2 \mathrm{H}+\mathrm{O}_{\mathrm{s}} \rightarrow \mathrm{H}_{2} \mathrm{O}+\mathrm{V}_{\mathrm{O}}
$$

$\mathrm{A}_{2} \mathrm{O}$ molecule and a surface oxygen vacancy $\left(\mathrm{V}_{\mathrm{O}}\right)$ are produced by the reaction. One possible assumption is that the nanoparticle turns black as the number of $\mathrm{V}_{\mathrm{O}}$ increases and that of $\mathrm{O}_{\mathrm{s}}$ decreases. In the following discussion, therefore, it is assumed that the whiteness of the nanoparticle is proportional to the coverage of the surface oxygen $\mathrm{O}_{\mathrm{s}}$.

If the number of $\mathrm{H}_{2}$ is enough and the Arrhenius type rate equation is assumed in this reaction, the coverage of surface oxygen $\left(\left[\mathrm{O}_{\mathrm{s}}\right]\right.$ ) obeys the following differential equation.

$$
\frac{\mathrm{d}\left[\mathrm{O}_{\mathrm{s}}\right]}{\mathrm{d} t}=-k_{1}\left[\mathrm{O}_{\mathrm{s}}\right]
$$

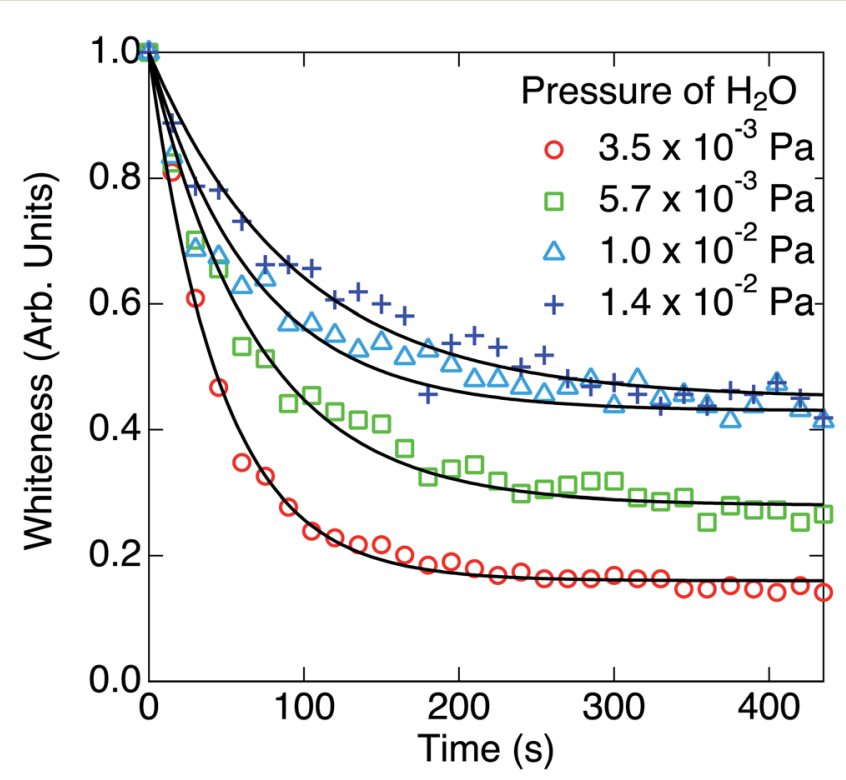

Fig. 6 Time evolutions of the whiteness at the partial pressures of $\mathrm{H}_{2} \mathrm{O}$ of $3.5 \times 10^{-3} \mathrm{~Pa}, 5.7 \times 10^{-3} \mathrm{~Pa}, 1.0 \times 10^{-2} \mathrm{~Pa}$ and $1.4 \times 10^{-2} \mathrm{~Pa}$. The ambient partial pressure of $\mathrm{H}_{2}$ was $3.3 \times 10^{-2} \mathrm{~Pa}$. The solid lines are exponentially fitted curves. 
Table 2 The reaction rate constants $\left(k^{\prime}\right)$, the saturation values $\left(w_{s}\right)$ of the time evolution of the whiteness at several partial pressures of $\mathrm{H}_{2} \mathrm{O}$, $k_{1}$ and $k_{2}$ estimated by the results in Fig. 6

\begin{tabular}{lcccc}
\hline$p_{\mathrm{H}_{2} \mathrm{O}} / \mathrm{Pa}$ & $k^{\prime} / \mathrm{s}^{-1}$ & $w_{\mathrm{s}}$ & $k_{1} / \mathrm{s}^{-1}$ & $k_{2} / \mathrm{s}^{-1}$ \\
\hline $3.50 \times 10^{-3}$ & 0.0215 & 0.16 & 0.018 & 0.003 \\
$5.70 \times 10^{-3}$ & 0.0146 & 0.28 & 0.011 & 0.003 \\
$1.0 \times 10^{-2}$ & 0.0146 & 0.43 & 0.008 & 0.006 \\
$1.40 \times 10^{-2}$ & 0.0100 & 0.44 & 0.006 & 0.004 \\
\hline
\end{tabular}

where $k_{1}$ is the reaction rate constant. Assuming that the whiteness is proportional to $\left[\mathrm{O}_{\mathrm{s}}\right]$, the time evolution of the whiteness $(W)$ can be written as follows,

$$
\begin{gathered}
W \propto\left[\mathrm{O}_{\mathrm{s}}\right] \propto \exp \left(-k_{1} t\right), \\
k_{1}=A_{1} \exp \left[-E_{\mathrm{a}} /\left(k_{\mathrm{B}} T_{\mathrm{s}}\right)\right],
\end{gathered}
$$

where $A_{1}$ is the frequency factor, $E_{\mathrm{a}}$ is the activation energy for the reaction (1), $T_{\mathrm{s}}$ is the temperature of the surface of $\mathrm{TiO}_{2}$, and $k_{\mathrm{B}}$ is the Boltzman constant. The reaction rate constants $\left(k_{1}\right)$ at the initial stages of the reaction are plotted against $p_{\mathrm{H}_{2}}$ in the inset of Fig. 1, which shows their proportionality. Since $T_{\mathrm{S}}$ is same for all curves in Fig. $1, k_{1}$ is proportional to the frequency factor $A_{1}$. At the initial stage of the reaction, the number of $\mathrm{O}_{\mathrm{s}}$ is enough, it is therefore suggested that the frequency factor depends on the number of incident $\mathrm{H}$ atoms. Since the incident frequency $(\Gamma)$ of $\mathrm{H}$ atoms is proportional to $\Gamma=p_{\mathrm{H}_{2}} / \sqrt{2 \pi m_{\mathrm{H}_{2}} k_{\mathrm{B}} T_{\mathrm{g}}}$, where $m_{\mathrm{H}_{2}}$ and $T_{\mathrm{g}}$ are the mass and the temperature of ambient $\mathrm{H}_{2}$ molecules, it is reasonable that the reaction rate constant is proportional to the ambient pressure of $\mathrm{H}_{2}$.

In Fig. 2, the whitenesses also change exponentially at the initial stages of the reaction. However, it is difficult to fit each curve by a single rate constant. The slopes of the curves significantly change in the blackening process. This suggests

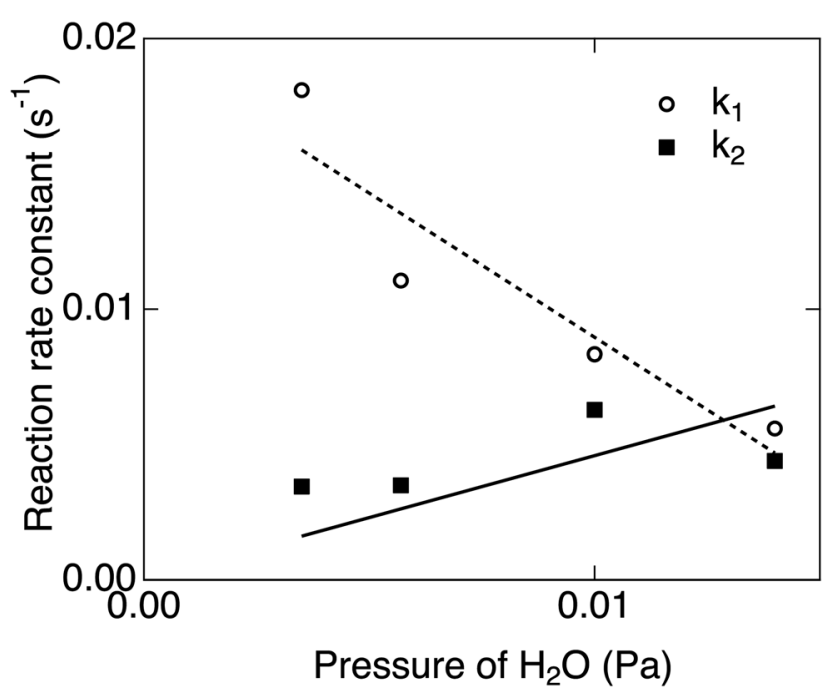

Fig. $7 p_{\mathrm{H}_{2} \mathrm{O}}$ dependences of $k_{1}$ and $k_{2}$ estimated from the rate constants and the saturation values of the whiteness in Fig. 6 . a possibility of the presence of two blackening processes with different reaction rate constant, although this cause is not known yet.

It should be noted that the absolute value of the reaction constant at $573 \mathrm{~K}$ in Fig. 2 is different from that at $1.0 \times 10^{-2} \mathrm{~Pa}$ in Fig. 1 in spite of the similar condition of reaction. As described in the Experimental section, this is because the distance between the sample and the $\mathrm{W}$ filament is different from each other. Though the absolute value of the rate constant cannot be discussed, the temperature dependence of the relative rate constant is discussed.

The Arrhenius plot for the reaction (eqn (4)) is plotted in the inset of Fig. 2. The activation energy for the reaction (1) was estimated to be $186 \pm 50 \mathrm{meV}$. Scheiber et al. reported that migration of $\mathrm{V}_{\mathrm{O}}$ from surface to subsurface starts at temperatures $\sim 200 \mathrm{~K}$, which suggests that diffusion of $\mathrm{O}$ from subsurface to surface also starts at such low temperatures. ${ }^{20}$ Therefore, it is suggested that the diffusion of $\mathrm{V}_{\mathrm{O}}$ or $\mathrm{O}$ are not a ratedetermining process for the reaction (1). Ohashi et al. reported that the tailing feature at the valence band maximum that is characteristic to the black $\mathrm{TiO}_{2}$ was not observed by annealing after $\mathrm{H}$ ion irradiation, where no structural disorder occurred by $\mathrm{H}$ incorporation in $\mathrm{TiO}_{2}$ without annealing. ${ }^{16}$ In the present work, on the other hand, the $\mathrm{TiO}_{2}$ could be blackened by annealing under the atomic $\mathrm{H}$ irradiation.

Since $\mathrm{H}_{2} \mathrm{O}$ is the product of the reaction (1), the reverse reaction also occurs if a large amount of $\mathrm{H}_{2} \mathrm{O}$ gas exists in the atmosphere.

$$
\mathrm{H}_{2} \mathrm{O}+\mathrm{V}_{\mathrm{O}} \rightarrow \mathrm{H}_{2}+\mathrm{O}_{\mathrm{s}}
$$

If the number of incident $\mathrm{H}_{2} \mathrm{O}$ gas is enough and the first order rate equation is also assumed in this reaction, the differential equation for the two reactions (1) and (5) can be written as follows.

$$
\begin{aligned}
& \frac{\mathrm{d}\left[\mathrm{O}_{\mathrm{s}}\right]}{\mathrm{d} t}=-k_{1}\left[\mathrm{O}_{\mathrm{s}}\right]+k_{2}\left[\mathrm{~V}_{\mathrm{O}}\right], \\
& \frac{\mathrm{d}\left[\mathrm{V}_{\mathrm{O}}\right]}{\mathrm{d} t}=k_{1}\left[\mathrm{O}_{\mathrm{s}}\right]-k_{2}\left[\mathrm{~V}_{\mathrm{O}}\right],
\end{aligned}
$$

where $\left[\mathrm{O}_{\mathrm{s}}\right]$ and $\left[\mathrm{V}_{\mathrm{O}}\right]$ are the coverages of surface oxygen and oxygen vacancy, respectively, which fulfils $\left[\mathrm{O}_{\mathrm{s}}\right]+\left[\mathrm{V}_{\mathrm{O}}\right]=1 . k_{1}$ and $k_{2}$ are the reaction rate constants of the two reactions (1) and (5), respectively. The solution of these differential equations is

$$
W=\frac{k_{1}}{k_{1}+k_{2}} \exp \left[-\left(k_{1}+k_{2}\right) t\right]+\frac{k_{2}}{k_{1}+k_{2}} .
$$

This solution is consistent with the trend of the exponential decay and the saturation of the whiteness in Fig. 6 .

The parameters $k_{1}$ and $k_{2}$ were estimated from the reaction rate constants $\left(k^{\prime}=k_{1}+k_{2}\right)$ and the saturation values of the whiteness $\left(w_{\mathrm{s}}=k_{2} /\left(k_{1}+k_{2}\right)\right)$ by fitting the experimental curves to eqn (8) in Fig. 6. They are summarized in Table 2 and plotted in Fig. 7. Though the trends of increasing of $k_{2}$ with increasing $p_{\mathrm{H}_{2} \mathrm{O}}$ are shown, the proportionality between $k_{2}$ and $p_{\mathrm{H}_{2} \mathrm{O}}$, which is expected under the assumption of a similar equation with eqn (4), is not clear. It is also suggested that the reaction (1) 
between $\mathrm{H}_{2}$ and $\mathrm{O}_{\mathrm{s}}$ is severely blocked by the presence of $\mathrm{H}_{2} \mathrm{O}$, by which $k_{1}$ largely decreases with increasing $p_{\mathrm{H}_{2} \mathrm{O}}$. Li and GaO reported that the surface $\mathrm{V}_{\mathrm{O}}$ becomes more stable than the subsurface $\mathrm{V}_{\mathrm{O}}$ by water adsorption, by which water dissociation can be activated. This may also increase $k_{2}$, which is consistent with our results in Fig. 7.

\section{Summary}

The blackening process of $\mathrm{TiO}_{2}$ nanoparticles by exposing to atomic hydrogen was studied. The whiteness of $\mathrm{TiO}_{2}$ decreased exponentially with time. Assuming that the whiteness is proportional to the coverage of the surface oxygen vacancy, the rate constant in the first order rate equation for the reaction between $\mathrm{H}_{2}$ and surface oxygen is proportional to the pressure (the impinging rate) of $\mathrm{H}_{2}$, and increases with increasing the hydrogenation temperature. The crystal size and the anatase/ rutile ratio were estimated by $\mathrm{XRD}$, which shows that the decrease in the fraction of anatase begins almost at the same hydrogenation temperature with the increase in the size of $\mathrm{TiO}_{2}$ nanoparticles. The blackening of $\mathrm{TiO}_{2}$ halfway stopped under the condition of the similar partial pressure of water with hydrogen. This suggests the presence of reverse reaction between $\mathrm{H}_{2} \mathrm{O}$ and oxygen vacancy and the presence of $\mathrm{H}_{2} \mathrm{O}$ severely blocks the reaction between $\mathrm{H}_{2}$ and surface oxygen. Tailing of the valence band maximum and the enhancement of photocatalytic reaction were confirmed for the single crystal $\mathrm{TiO}_{2}$ blackened by the same method, and the surface structure is under study. ${ }^{21}$ It is expected that our new method would contribute the efficiency improvement of photocatalyst based on $\mathrm{TiO}_{2}$.

\section{Conflicts of interest}

There are no conflicts to declare.

\section{Acknowledgements}

This work was partly supported by Grants-in-Aid for Scientific Research (JSPS KAKENHI under Grant No. JP17K05052 and JP18H05518).

\section{References}

1 A. Fujishima and K. Honda, Nature, 1972, 238, 37.

2 U. Diebold, Surf. Sci. Rep., 2003, 48, 53.

3 R. Asahi, T. Morikawa, T. Ohwaki, K. Aoki and Y. Taga, Science, 2001, 293, 269.

4 S. Soni, M. Henderson, J.-F. Bardearu and A. Gibaud, Adv. Mater., 2008, 130, 5018.

5 X. Chen and C. Burda, J. Phys. Chem. B, 2004, 108, 15449.

6 X. Chen and C. Burda, J. Am. Chem. Soc., 2008, 130, 5018.

7 F. Zuo, L. Wang, Z. Zhang, D. Borchardt and P. Feng, J. Am. Chem. Soc., 2010, 132, 11856.

8 X. Chen, L. Liu, P. Yu and S. Mao, Science, 2011, 331, 746.

9 X. Chen, L. Liu, Z. Liu, M. Marcus, W.-C. Wang, N. Oyler, M. Grass, B. Mao, P.-A. Glans, P. Yu, J. Guo and S. Mao, Sci. Rep., 2013, 3, 1510.

10 L. Liu, P. Yu, X. Chen, S. Mao and D. Shen, Phys. Rev. Lett., 2013, 111, 065505.

11 X. Liu, G. Zhu, X. Wang, X. Yuan and T. Lin, Adv. Energy Mater., 2016, 6, 1600452.

12 S. Selcuk, X. Zhao and A. Selloni, Nat. Mater., 2018, 17, 923.

13 H. Liu, H. Ma, X. Li, W. Li, M. Wu and X. Bao, Chemosphere, 2003, 50, 39.

14 Z. Lu, C.-T. Yip, L. Wang, H. Huang and L. Zhou, ChemPlusChem, 2012, 77, 991.

15 K. Fukada, M. Matsumoto, K. Takeyasu, S. Ogura and K. Fukutani, J. Phys. Soc. Jpn., 2015, 84, 064716.

16 Y. Ohashi, N. Nagatsuka, S. Ogura and K. Fukutani, J. Phys. Chem. C, 2019, 123, 10319.

17 Y. Li and Y. Gao, Phys. Rev. Lett., 2014, 112, 206101.

18 A. Sutoh, Y. Okada, S. Ohta and M. Kawabe, Jpn. J. Appl. Phys., 1995, 34, L1379.

19 W. Mao, M. Wilde, S. Ogura, J. Chen, K. Fukutani, H. Matsuzaki and T. Terai, J. Phys. Chem. C, 2018, 122, 23026.

20 P. Scheiber, M. Fidler, O. Dulub, M. Schmid, U. Diebold, W. Hou, U. Aschauer and A. Selloni, Phys. Rev. Lett., 2012, 109, 136103.

21 M. Fujimoto, M. Matsumoto, N. Nagatsuka and K. Fukutani, in preparation. 